March - 2010

\title{
The Comparative Instructional Effectiveness of Print-Based and Video-Based Instructional Materials for Teaching Practical Skills at a Distance
}

\author{
Francis Donkor \\ University of Education, Winneba, Ghana
}

\begin{abstract}
Print-based instructional materials have been more popular than any other medium for teaching practical skills during the delivery of technical and vocational education and training via distance learning. However, the approach has its shortcomings and in recent times alternatives have been sought. The comparative instructional effectiveness of one such alternative is the focus of this paper. The study sought to examine the instructional effectiveness of video-based instructional materials vis-à-vis traditional print-based instructional materials for teaching distance learners of a Block-Laying and Concreting practical skills programme. An experimental design was used and participants were randomly assigned to two treatment groups: Users of video-based instructional materials or users of print-based instructional materials. A researcher-designed performance test and an achievement test of 20 multiple-choice items were used to collect data from 34 participants who used print-based instructional materials and 35 participants who used video-based instructional materials to learn practical skills. The instruments were based on the instructional objectives of lessons on mortar and wall finish. Pilot test data for the achievement test yielded Cronbach's alpha of 0.84. Descriptive statistics and t-test at a 0.05 level of significance were used to analyse the data. The results indicated that the two instructional materials were pedagogically equivalent in terms of theoretical knowledge acquired. Practical skills acquired, however, were significantly higher among users of video-based instructional materials. Finally, users of video-based instructional materials displayed significantly superior craftsmanship.
\end{abstract}

Keywords: Achievement test; block-laying and concreting; instructional effectiveness; open and distance learning; open schooling; performance test; practical skills; print-based instructional materials; technical and vocational education and training (TVET); video-based instructional materials

\section{Teaching Practical Skills to Distance Learners}

Distance education as a delivery mechanism has been relatively more successful in the academic field than in the field of technical and vocational education and training (TVET). The practical 
nature of TVET disciplines mostly accounts for the situation. For the open and distance learning (ODL) environment, the teaching of practical skills poses considerably more difficulties than the teaching of knowledge and theory (Hampton, 2002). Examining the future of open schooling, Ferreira (2009, p. 202) observed that "the provision of technical and vocational course subjects represents, for many countries, a national challenge" and that "success in delivering the practical components depends on collaboration amongst the different stakeholders.” The successful teaching of practical skills could thus hold the key to the successful delivery of TVET via ODL.

The teaching of practical skills requires the use of precise instructions to enable learners to follow the process and thereafter repeat the skill, whether within a conventional educational institution or via distance learning. In a typical conventional classroom-based educational institution, an instructor provides such instructions in workshops and laboratories using the appropriate materials and equipment. For open and distance learners who are separated from the instructor much of the time, the most frequently used method for teaching practical skills, according to Hampton (2002), is the use of print-based illustrations of step-by-step procedures. This approach has its shortcomings and, therefore, in recent times alternatives have been sought. One such alternative used by The President's Special Initiative on Distance Learning in the delivery of Block-Laying and Concreting via distance learning in Ghana is video-based practical lessons, the comparative effectiveness of which is the focus of this paper.

The use of video in the delivery of practical lessons is acknowledged in the literature. For example, Mishra (2001) observed that video is useful to show practical and real life activities and that video can be used to capture hazardous and costly experiments for presentation and for repeated use. Tooth (2000) also observed that video resources are expensive to produce but are very useful where practical demonstrations of skills are required. For Jung (2005), however, cost-savings are expected from reuse of video resources. The decision of ODL practitioners to use video-based instructional materials to teach practical skills in spite of the relatively high cost will to a large extent depend on the assurance of their guaranteed instructional effectiveness. Empirical research into the effectiveness of video-based instructional materials for the teaching of practical skills at a distance may be necessary to provide reason for their use or otherwise.

\section{The President's Special Initiative on Distance Learning Open Schooling in TVET}

The Ghana Government has realised the need to find alternate means of responding to the educational needs of her people. It therefore established The President's Special Initiative on Distance Learning (PSI-DL) in April, 2002 to co-ordinate and implement alternate models of education that complement Government's efforts to ensure that Ghana attains the target of “Education for All” by 2015. Accordingly, PSI-DL began to broadcast television lessons on state television, which has nation-wide coverage, on July 23, 2003. The lessons are based on the Ghana Education Service syllabus for the junior and senior high schools. Subjects covered include English, mathematics, physics, chemistry, biology and integrated science. 
PSI-DL started its open schooling in TVET at the pre-tertiary level in September, 2007 on a pilot basis using learning centres in the existing six TVET institutions and in five prisons in Ghana. The courses selected for the pilot are Block-Laying and Concreting and Catering. Worldwide, open schooling is a response to the rapidly increasing demand for secondary education, both as an end itself and as a route to tertiary education and training (Daniel, 2008). In the view of Daniel, open schooling has also become "a vehicle for ramping up the proportion of technical and vocational education and training in the school system as a whole...” (p. 43). Similarly, the PSI-DL Open Schooling in TVET is a means to increase the proportion of TVET in the school system in Ghana. Two different approaches to open schooling have been identified by Rumble and Koul (2007), one complementary to the conventional school system and the other alternative to the conventional school system. The PSI-DL Open Schooling in TVET operates as a complementary system offering the same curriculum for the youth and young adults who, for a variety of reasons, miss the formal, classroom-based school system. Similar to their counterparts in the conventional classroom-based school system, the distance learners are prepared to take the same Intermediate Craft Examination organised by the Technical Examinations Unit of the Ghana Education Service.

\section{Rationale}

TVET has been identified as crucial to the achievement of the Millennium Development Goal of eradicating extreme poverty and hunger by 2015. It has the potential to make huge gains in poverty reduction and wealth creation. This fact has been well articulated by the National Development Planning Commission (2005) in the Ghana Growth and Poverty Reduction Strategy (2006-2009) document, which acknowledges a strong linkage between TVET and poverty reduction. Additionally, the aspiration of Ghana to become a middle income earning economy depends largely on the ability to equip her citizens with knowledge and skills to produce quality goods and services on a continuous basis for income. The acquisition of skills is also a way of sustaining the sociopolitical stability of the nation. Based on these realisations, the PSI-DL Open Schooling in TVET was initiated to enable unemployed youth to have the opportunity to acquire skills for sustainable livelihoods and to enhance their chances in the labour market.

\section{Target Group and Objectives}

The PSI-DL Open Schooling in TVET is at the post junior high school level and targets the youth and young adults who, for a variety of reasons, have not been part of the formal, classroom-based school system. The program seeks to equip the learners with skills to enable them to do the following:

1. set up their own businesses,

2. work in industries, or

3. move on to the tertiary level for further education. 


\section{Instructional Materials}

Under the PSI-DL Open Schooling in TVET, learners are provided with self-instructional materials (as a tutor-in-print/substitute for the teacher) to study at home on their own. During face-to-face sessions that take place fortnightly at learning centres established in existing conventional technical and vocational institutions, the learners also get local personal support in the form of tutorials, counselling, access to practical lessons, self-help study group activities, etc. The learning of theory is through print-based instructional materials. Regarding acquisition of practical skills, learners initially use either print-based illustrations of step-by-step procedures or video-based practical lessons. In the case of the latter, the practical aspects of the course are converted into production scripts then shot, edited, and dubbed onto VCDs. The learners access the practical lessons using computers or VCD players in their homes or at the learning centres. Practical skills acquisition is finally consolidated through hands-on activities in the workshops and laboratories during face-toface sessions at the learning centres under the supervision of an instructor/tutor.

\section{The Problem Statement}

For the teaching of practical skills to open and distance learners, Hampton (2002, p. 85) sees video as "a successful medium because it links the audio and the visual together to provide a multisensory experience for the learner." Hampton observes that video makes it possible for the learner to play, replay, pause and rewind to specific sections of the lesson and further contends that "because practice and rehearsal is so important in developing competency, video is particularly well placed" (p. 85). In spite of the foregoing, not much is encountered in literature regarding empirically documented works about the instructional effectiveness of video vis-à-vis other approaches for the teaching of practical skills to open and distance learners. This void in literature needs to be filled in order to increase our understanding of the relative effectiveness of the various approaches used in teaching practical skills via distance learning.

As already indicated above, PSI-DL has produced practical lessons on VCDs and print-based materials for teaching practical skills to its distance learners. However, there has not been any assessment regarding their relative instructional effectiveness. In view of this, the present study was undertaken to provide feedback regarding the comparative instructional effectiveness of the two approaches to teaching practical skills to distance learners, while at the same time attempting to fill the identified gap in literature.

\section{Purpose of the Study}

This was an exploratory study that sought to examine the effectiveness of the video-based instructional materials (practical lessons on VCDs) vis-à-vis the traditional print-based instructional materials for the teaching of practical skills to distance learners of a Block-Laying and Concreting programme. Specifically, the study was designed to compare the level of learning (in terms of theoretical knowledge and practical skills acquisition) between learners using video-based 
instructional materials and those using print-based instructional materials in relation to the instructional objectives of the lessons on mortar and wall finish.

\section{Research Questions}

The following research questions guided the study:

1. How do learners using video-based practical lessons and those using print-based practical lessons compare in practical skills acquisition?

2. How do learners using video-based practical lessons and those using print-based practical lessons compare in theoretical knowledge?

3. How do learners using video-based practical lessons and those using print-based practical lessons compare in their craftsmanship?

\section{Methodology}

\section{Research Design}

The study used experimental design. As the study sought to compare the level of learning (in terms of knowledge and practical skills acquisition and craftsmanship) between learners using videobased instructional materials and those using print-based instructional materials, the experimental design was deemed appropriate. The main variables involved were level of learning as the dependent variable and instructional materials (video-based and print-based) as the independent variables.

Generally, there are three ways to assign participants to experimental conditions: a betweensubjects design (sometimes called an independent-group design), a within-subjects design (also called a repeated-measures design), and a mixed design (Vernoy \& Kyle, 2002). Each of the learners selected for the study participated in only one of the two experimental conditions making the study a between-subjects design. According to Vernoy and Kyle, a between-subjects design requires that "each level of each independent variable has different participants; thus, there is a distinct difference between each level of the experiment because each person participates in one and only one level” (p. 259).

\section{Population and Sample}

The population comprised all 151 learners who registered for Block-Laying and Concreting during the 2007/2008 academic year at the five learning centres (institutions) offering the subject via distance learning. They were all males. This is consistent with male dominance in Block-Laying and Concreting in the formal, classroom-based school system, owing to gender stereotyping.

The study sample consisted of all 73 learners of three study centres purposely drawn from three zonal divisions in Ghana, namely Bolgatanga Technical Institute for the Northern Zone, Ramseyer 
Vocational and Technical Institute, Kumasi for the Middle Zone, and Takoradi Technical Institute for the Southern Zone. The learners from each selected study centre were assigned randomly to two treatment groups as indicated in Table 1: learners using video-based instructional materials and those using print-based instructional materials.

Table 1

Distribution of Study Sample according to Experimental Conditions

\begin{tabular}{lllc}
\hline Study centre (institution) & \multicolumn{2}{l}{ Number of learners } & \multirow{2}{*}{ Total } \\
\cline { 2 - 3 } & $\begin{array}{l}\text { Video-based } \\
\text { group }\end{array}$ & $\begin{array}{l}\text { Print-based } \\
\text { group }\end{array}$ & \\
\hline Bolgatanga Technical Institute, Bolgatanga & 13 & 12 & 25 \\
Ramseyer Vocational and Technical Institute, Kumasi & 7 & 8 & 15 \\
Takoradi Technical Institute, Takoradi & 16 & 17 & 33 \\
Total & 36 & 37 & 73 \\
\hline
\end{tabular}

\section{Instruments}

The study used two instruments to collect data to answer the three research questions posed. The two instruments were based on the instructional objectives of lessons on mortar and wall finish. The first instrument was an achievement test that sought to measure the level of theoretical knowledge acquired after learners had been exposed to theoretical lessons from print-based instructional materials (manuals) and the practical lessons from either the video-based or print-based materials. It consisted of 20 objective test items with 10 items on mortar and 10 items on wall finish (see Appendix A). Each item had four options of responses. The second instrument was a performance test that sought to measure the level of practical skills acquired by learners after exposure to the practical lessons from either the video-based or print-based materials. The participants were instructed to perform certain tasks so as to demonstrate certain skills acquired (see Appendix B). The marking schemes for scoring both tests appear in Appendix C.

Content validity of the instruments was established by a panel of four Block-Laying and Concreting tutors out of 12 research assistants recruited for the study. The research assistants were all tutors of Block-Laying and Concreting and long-serving examiners at the Intermediate Craft level of the Technical Examinations Unit of the Ghana Education Service. The questionnaire was pre-tested using a sample of 20 randomly selected full-time students from one of the institutions that constituted the population but was not selected for the study. The sample size of 20 for the pilot study was based on the observation of Borg and Gall (1983) that for a pilot study it is rarely necessary to include more than 20 subjects. 
The researcher personally administered the achievement test to the 20 students after they had completed the lessons on the two selected topics that formed the scope of the study, namely mortar and wall finish. Before administering the test, the purpose of the study was explained to the students and they were asked to underline words they did not understand. To ensure anonymity, the participants were asked to write only their index numbers but not their names. Additionally, they were advised to do independent work. At the start of the exercise, the time was recorded. On submission of the test, the time was again recorded on the individual's test paper so as to determine the time taken by each participant to complete the test. In all, the participants spent between 23 and 38 minutes to complete the test. As and when the participants completed the achievement tests and handed them in, the tests were scrutinised to ensure that they had been properly completed.

After the administration of the achievement test, four out of the 20 students were selected randomly to participate in the piloting of the performance test. One student at a time undertook the exercise and all four research assistants involved in the validation of the instruments scored them independently. After assessing the four students, the researcher and the four research assistants met to discuss the scoring in relation to the marking scheme. For all four research assistants, the scores for each competency as specified in the marking scheme were discussed. After the discussions, we agreed on common strategies that could help to reduce subjectivity during the scoring process and thus minimise variability.

The achievement test was scored by awarding one mark for each correct response and zero for incorrect alternatives. After scoring, item-analysis was carried out to determine the difficulty level of the items, the discriminating power of the items, and the effectiveness of the options of responses (distracters). The item analysis indicated that the difficulty level and the discriminating power of each of the 20 test items were acceptable. Additionally, the analysis of the distracters indicated that for all 20 items, the options appeared plausible to the respondents, (i.e., the alternatives functioned as intended). Thus, it was concluded that there were no ambiguous test items or flawed options that needed revision.

Cronbach's alpha reliability test for the achievement test yielded a value of 0.84 . Against the background of the observation byJohnson and Larry (2008, p. 149) that "A popular rule of thumb is that the size of coefficient alpha should generally be, at a minimum, greater or equal to .70 for research purposes," this value of reliability indicates good internal consistency and instrument reliability. Beside the item analysis and the reliability test, words that participants did not understand were identified and revised accordingly.

\section{Data Collection Procedures}

The scoring of any performance test requires converting qualitative indicators of competencies into numeric (quantitative) values for each indicator. Such an exercise is generally subjective, and there could be variability and lack of reliability across different scorers. In the present study, therefore, each participant was assessed by three research assistants and any two scores with the lowest variability were averaged to produce a composite score for the participant. In furtherance of measures to minimise variability in the scoring, the 12 research assistants first met to discuss the 
performance test and the scoring process using the marking scheme (Appendix C) as a uniform standard of measurement. The four research assistants who participated in the pilot study facilitated the discussions.

The data collection took three days, with a day at each of the three participating learning centres. The participants were assigned index numbers for use in both tests. At each centre, the researcher personally administered the achievement test which was followed by the performance test. All the participants took the achievement test together, whilst a maximum of four participants took the performance test at a time. The achievement test was administered and scored in a manner similar to the pilot study. On each occasion of administering the achievement test, two of the research assistants were in attendance as invigilators. The participants were adequately spaced to ensure that they worked independently. As and when the participants completed the achievement test and handed them in, they were scrutinised to ensure that they had been completed properly, especially the index numbers. The administration of the achievement test took less than forty minutes, similar to the pilot test.

For the purpose of scoring the performance test, the eight research assistants who did not participate in the pilot study were assigned randomly into four groups; the four who participated in the pilot study were also assigned randomly to the four groups of scorers as team leaders. At each sudy centre, the researcher re-constituted the groups as described above. During the administration of the performance test, four students were selected randomly from a given treatment group and assigned randomly to the respective four groups of scorers. The necessary materials and working area were provided. All three research assistants in each group of scorers scored the work of the participants assigned to them independently, using the marking scheme in Appendix C, without knowing the treatment group the participants belonged to. It was also arranged in such a way that participants who completed the performance test could not communicate with those awaiting their turn.

A total of 69 out of the 73 selected distance learners took part in the study, representing an overall response rate of 94.5\%. This included 35 out of the selected 36 (representing 97.2\% response rate) users of video-based instructional materials and 34 out of the selected 37 (representing 91.9\% response rate) users of print-based instructional materials.

\section{Method of Data Analysis}

The data analysis focused on the comparison of the cognitive and psychomotor impacts of the two instructional materials. Regarding the cognitive impact, the study addressed the question: How do learners using video-based practical lessons and those using print-based practical lessons compare in theoretical knowledge? With regard to the psychomotor impact, the study addressed two questions:

1. How do learners using video-based practical lessons and those using print-based practical lessons compare in practical skills acquisition?

2. How do learners using video-based practical lessons and those using print-based practical lessons compare in their craftsmanship? 
The raw data were analysed, using the Statistical Package for the Social Sciences (SPSS). First, descriptive statistics such as frequency counts, percentages, means and standard deviations were used to analyse the data collected. Second, t-test at a 0.05 level of significance was used to determine whether the two treatment groups differed regarding theoretical knowledge and practical skills acquired and the craftsmanship displayed during the performance of the hands-on activity assigned to them.

\section{Results and Discussion}

The research findings are presented in three sections according to the three research questions that guided the study.

1. How do learners using video-based practical lessons and those using print-based practical lessons compare in practical skills acquisition?

The level of practical skills acquired by the participants was measured by the performance test in Appendix B. The distribution of the performance test scores (out of a possible 50) showed that the group that used print-based instructional materials to learn practical skills had scores ranging from 23.5 to 40.5 , while the group that used video-based instructional materials had scores ranging from 26.0 to 43.0. For the users of the print-based instructional materials, the modal score was 31.0 with a frequency of three. The modal score for users of the video-based instructional materials was 40.0 with a frequency of three. The mean score for the group that had used print-based instructional materials to learn practical skills was $31.84(S D=4.85)$. For the group that had used video-based instructional materials to learn practical skills, the mean score was $35.20(S D=5.44)$.

To compare the instructional effectiveness of the two instructional materials for learning practical skills at a distance, the mean scores of the two treatment groups in the performance test were compared using t-test at the 0.05 level of significance. The results of the t-test analysis are presented in Table 2. The results indicated that the performance test scores of the group that used video-based instructional materials to learn practical skills were significantly higher than those who used print-based instructional materials ( $p$-value $<0.05$ ). Thus, the video-based instructional materials were more effective than the print-based instructional materials in equipping the distance learners with practical skills. 
The Comparative Instructional Effectiveness of Print-Based and Video-Based Instructional Materials for Teaching Practical Skills at a Distance - Donkor

Table 2

Results of T-Test Analysis for the Performance Test

\begin{tabular}{|c|c|c|c|c|c|}
\hline Treatment group & $\begin{array}{l}\text { No. of } \\
\text { respondents }\end{array}$ & $x$ & SD & $\mathrm{t}$ & p-value \\
\hline Print-based & 34 & 31.84 & 4.85 & & \\
\hline Video-based & 35 & 35.20 & 5.44 & $2.668^{*}$ & 0.009 \\
\hline
\end{tabular}

* Significant at 0.05 level

The practical nature of TVET disciplines makes its delivery via distance learning more challenging than in the academic field. Traditionally, print-based instructional materials have been used for teaching distance learners practical skills. In the present study, video-based instructional materials were found to be pedagogically more effective than the print-based instructional materials in the delivery of Block-Laying and Concreting via distance learning. It is the researcher's view that this relatively unexplored area of ODL has been investigated to a limited extent. Additional research is needed to determine the effectiveness of video-based instructional materials in the teaching of practical skills in other disciplines of TVET. This would offer ODL practitioners better insight into the real effectiveness of video-based instructional materials in the teaching of practical skills.

2. How do learners using video-based practical lessons and those using print-based practical lessons compare in theoretical knowledge?

The theoretical knowledge acquired by the distance learners was measured by the achievement test that appears in Appendix A. The distribution of the achievement test scores (out of a possible 20) showed that users of the print-based instructional materials had scores ranging from 9 to 20. Users of the video-based instructional materials had scores ranging from 10 to 20 . The modal score for the users of print-based instructional materials was 13 with a frequency of eight. The other treatment group had a modal score of 15 with a frequency of seven. The mean score for the group that used print-based instructional materials to learn practical skills was $14.82(S D=2.50)$. For the group that used video-based instructional materials to learn practical skills, the mean score was 14.86 ( $S D=$ 2.59).

To compare the instructional effectiveness of the two instructional materials regarding acquisition of theoretical knowledge, the mean scores in the achievement test of the two treatment groups were compared using t-test at the 0.05 level of significance. Table 6 shows the results of the t-test analysis. Though the treatment group that used video-based instructional materials appeared to perform better than those who used print-based instructional materials, the difference was not significant ( $p$-value $>0.05$ ). Thus, the two instructional materials are comparable and pedagogically equivalent regarding their effectiveness in equipping distance learners with theoretical knowledge. 
Table 3

Results of T-Test Analysis for the Achievement Test

\begin{tabular}{llllll}
\hline Treatment group & $\begin{array}{l}\text { No. of } \\
\text { respondents }\end{array}$ & $\bar{x}$ & SD & t & p-value \\
\hline Print-based & 34 & 14.82 & 2.50 & & \\
& & & & $0.054^{*}$ & 0.956 \\
Video-based & 35 & 14.86 & 2.59 & & \\
\hline
\end{tabular}

*Non significant at 0.05 level

Practical lessons could help reinforce theoretical knowledge acquired by learners, especially in the field of technical and vocational education and training. In the present study, the theoretical knowledge acquired did not differ significantly between users of print-based instructional materials and users of video-based instructional materials. The lack of significant difference may be due to the effectiveness of the study materials provided to learners for the teaching and learning of the theoretical aspects of Block-Laying and Concreting, which makes it possible for similar levels of achievement among the users. Alternatively, the two approaches to the teaching of practical skills could have helped to raise the theoretical knowledge acquired by the learners but to comparable levels among the two treatment groups. Thus, the two instructional materials were pedagogically equivalent in terms of theoretical knowledge acquired.

3. How do learners using video-based practical lessons and those using print-based practical lessons compare in their craftsmanship?

The term craftsmanship as used in this study refers to the learner's display of a clean working environment, the correct handling of tools and equipment, the effective use of time, the consciousness of safety, and the judicious use of materials during hands-on practical activity. It formed the last section of the marking scheme for scoring the performance test (see Appendix C). The distribution of the craftsmanship scores (out of a possible 6) indicated that the scores for the group that used print-based materials ranged from 2.0 to 5.0, while the other group obtained scores ranging from 2.5 to 5.0. The modal score for the users of print-based instructional materials was 4.0 with a frequency of eight. The other treatment group had a modal score of 4.5 with a frequency of nine. The mean score for the group that used print-based instructional materials to learn practical skills was $3.26(S D=0.88)$. For the group that used video-based instructional materials to learn practical skills, the mean score was $3.91(S D=0.73)$.

To compare the instructional effectiveness of the two instructional materials regarding craftsmanship, the mean scores of the two treatment groups were compared using t-test at the 0.05 level of significance. The results of the t-test analysis are presented in Table 4 . The results indicated that the craftsmanship scores of the group that used video-based instructional materials to learn practical skills were significantly higher than those who used print-based instructional materials ( $p$ - 
value $<0.05)$. Thus, the video-based instructional materials were more effective than the printbased instructional materials in equipping the distance learners with the desired craftsmanship.

Table 4

Results of T-Test Analysis for Craftsmanship Displayed

\begin{tabular}{|c|c|c|c|c|c|}
\hline Treatment group & $\begin{array}{l}\text { No. of } \\
\text { respondents }\end{array}$ & $\bar{x}$ & SD & $\mathrm{t}$ & p-value \\
\hline Print-based & 34 & 3.25 & 0.88 & & \\
\hline Video-based & 35 & 3.91 & 0.73 & $3.409^{*}$ & 0.001 \\
\hline
\end{tabular}

*Significant at 0.05 level

The study found that the users of video-based instructional materials demonstrated superior levels of craftsmanship compared to the users of print-based instructional materials. Thus, users of videobased instructional materials are more likely to spend relatively less time performing specific tasks during practical lessons. Additionally, there would be less spoilage/wastage of consumables, reduced incidence of damage to equipment, and reduced accidents among users of video-based instructional materials during hands-on practical lessons. The identified benefits associated with the use of video-based instructional materials in teaching practical lessons could help to reduce costs when there is less spoilage/waste of materials, reduced injuries to learners, and reduced damage to equipment. This could help to compensate for the cost of producing the practical lessons on VCDs for use by distance learners.

\section{Conclusion and Implications for Practice}

The PSI-DL Open Schooling in TVET runs the Block-Laying and Concreting programme via distance learning at the pre-tertiary level. The practical aspect of the programme is delivered through print-based and video-based instructional materials. The present study sought to compare the instructional effectiveness of the two approaches in teaching practical skills to distance learners.

The findings of the study suggest that the video-based instructional materials are pedagogically superior to the print-based instructional materials as users of the former exhibited superior skills acquisition and craftsmanship. The two instructional materials were however found to be pedagogically equivalent in terms of the teaching and learning of theory. The comparative instructional effectiveness of different approaches used in teaching practical skills appears to be an unexplored area of ODL and has been investigated to a limited extent in this exploratory study. Additional research is suggested to determine the effectiveness of video-based instructional materials for the teaching of practical skills in other disciplines of TVET.

Though the use of video-based instructional materials may have cost implications, their superior instructional effectiveness in the teaching of practical skills is not in doubt. Additionally, the use of 
video-based instructional materials for teaching practical lessons is associated with such benefits as reduced cost of organising practical lessons due to less spoilage/waste of materials, reduced injuries to learners, and reduced damage to equipment. These benefits could help to compensate for the cost of producing the practical lessons on VCDs for use by open and distance learners. Thus, as much as possible, when selecting delivery options for the teaching and learning of practical skills,

decision-makers and ODL practitioners should rank them above print-based materials for their pedagogical impact. 


\section{References}

Borg, W. R., \& Gall, M. D. (1983). Educational research: An introduction. New York: Longman.

Daniel, J. (2008). Open schooling - Communicating the basics. In R. Jones-Parry (Ed.), Commonwealth education partnerships 2008/2009 (pp. 41 - 43). Cambridge, UK: Nexus Strategic Partnership.

Ferreira, F. (2009). The bright but challenging future of open schooling. In D.A.M.X. Abrioux \& F. Ferreira (Eds.), Perspectives on distance education: Open schooling in the 21st Century (pp. 193-204). Vancouver, Canada: Commonwealth of Learning. Retrieved from http://www.col.org/SiteCollectionDocuments/OpenSchooling_web.pdf

Hampton, C. (2002). Teaching practical skills. In A. K. Mishra \& J. Bartram (Eds.), Perspectives on distance education: Skills development through distance education (pp. 83-91). Vancouver, Canada: Commonwealth of Learning. Retrieved from http://www.col.org/SiteCollectionDocuments/Skills Chapter09.pdf

Johnson, R.B., \& Larry, B. (2008). Educational research: Quantitative, qualitative and mixed approaches ( $3^{\text {rd }}$ ed.). Thousand Oaks, CA: Sage.

Jung, I. (2005). Innovative and good practices of open and distance learning in Asia and the Pacific (A study commissioned by UNESCO, Bangkok). Retrieved from http://www.unescobkk.org/fileadmin/template2/apeid/odl_innov.pdf

National Development Planning Commission. (2005). Ghana growth and poverty reduction strategy (2006-2009). Accra: Author.

Mishra, S. (2001). Designing online learning. Vancouver, Canada: Commonwealth of Learning. Retrieved from http://www.col.org/SiteCollectionDocuments/KS2001-02 online.pdf

Rumble, G., \& Koul, B.N. (2007). Open schooling for secondary and higher secondary education: Costs and effectiveness in India and Namibia. Vancouver, Canada: Commonwealth of Learning. Retrieved from http://www.col.org/SiteCollectionDocuments/Open_Schooling_Secondary_Higher_Educati on 071707.pdf

Tooth, T. (2000). The use of multi media in distance education. Vancouver, Canada: Commonwealth of Learning. Retrieved from http://www.col.org/SiteCollectionDocuments/KS2000\%20multimedia.pdf

Vernoy, M., \& Kyle, D. (2002). Behavioral statistics in action ( $3^{\text {rd }}$ ed.). Boston: McGraw-Hill. 


\section{Appendix A}

\section{Achievement Test}

\section{Index Number:}

This test consists of multiple-choice items on 'Mortar' and 'Wall Finish'. Each question is followed by four options lettered A to D. Find out the correct option for each question and kindly circle the letter bearing that option. Give only one answer to each question.

\section{Answer all questions}

1. The ease with which mortar can be worked with is termed
A. flexibility
B. workability*
C. retentivity
D. durability

2. Which of the following mix proportions may not be appropriate for preparing cement-sand mortar for rendering?
A. $1: 4$
B. $1: 5$
C. $1: 6$
D. $1: 9 *$

3. What is the composition of 'compo mortar'?
A. Sand, cement and additive
B. Sand, cement and lime*
C. Sand and cement
D. Sand and lime

4. The function of plasticizers in mortar is to...........
A. give the mortar strength*
B. start the chemical reaction in the cement
C. reduce shrinkage in the cement
D. coat and bind the fine aggregate

5. Which of the following materials is first put into the mixing drum during machine mixing of mortar? 

A. Sand
B. Cement
C. Water*
D. Additives

6. The function of 'palm chaff' in clay mortar is to............
A. provide colour
B. increase the strength*
C. provide colour and strength
D. speed up the setting

7. Which of the following statement(s) about mortar is/are correct?

I. Mix proportion can only be determined when the work to be done is known.

II. During batching of materials the headpan is preferred to the gauge box.

III. Lime mortar can be re-activated by re-mixing and re-used.
A. I only
B. I and II only
C. I and III only*
D. II and III only

8. Which of the following statement(s) about water used in mortar preparation is/are true?

I. It must be as good as drinking water.

II. It starts the chemical reaction in the cement.

III. It reduces the heat in the cement.
A. I and II only
B. I and III only
C. II and III only
D. I, II and III*

9. Which of the following is not used during manual preparation of mortar?
A. Mixing drum*
B. Head pan
C. Dumper
D. Wheel barrow

10. What is the reason for using 'compo mortar' in plastering?
A. To provide colour. 
B. To increase strength.

C. To provide colour and strength.

D. To reduce cost.*

11. The coat applied to the uneven surface of the internal block work to provide an even surface is called.
A. brown coat
B. putty coat
C. scratch coat*
D. green coat

12. The ability of mortar under stress to elongate before breaking under stress is termed...
A. flexibility*
B. plasticity
C. consistency
D. durability

13. Which of the following is not a function of plastering?
A. To give a smooth surface
B. To form a base for receiving other finishes like paint
C. To help regulate temperature*
D. To give strength to the wall

14. Which of the following statement(s) about plastering is/are correct?

I. It is a three coat work.

II. It is a one coat work.

III. The thickness of the brown coat is smaller than the scratch coat.
A. I only
B. I and II only
C. I and III only*
D. II and III only

15. Another name for the pebble-dash finish is .......
A. wet-dash finish
B. dry-dash finish*
C. spatter-dash finish
D. Tyrolean finish 
16. Which of the following tools is not used during plastering?
A. Chisel
B. Bolster*
C. Hawk
D. Comb hammer

17. What tool is used in receiving mortar to seal crevices (small holes) that are left after scrubbing off excess mortar during plastering/ rendering?
A. Pointing trowel*
B. Plaster's trowel
C. Hand trowel
D. Hawk

18. The best remedy for shrinkage as a plastering/rendering problem is to......
A. treat the surface well before work proceeds.
B. allow mortar to dry before floating.
C. increase the water content in the mortar.
D. minimise cement content in the mortar.*

19. Which of the following is not a problem that arises in plastering/rendering works?
A. Blistering
B. Swell-outs
C. Fall off
D. Wrinkling*

20. Which of the following statements, being reasons for watering the base that is to receive plaster, are true?

I. Prevent shrinkage.

II. Wash off accumulated dirt on walls.

III. Help mortar to adhere properly to wall.
A. I and II only
B. I and III only*
C. II and III only
D. I, II and III

END OF TEST 


\section{Appendix B}

\section{PERFORMANCE TEST}

Index Number:

Time allowed: 1 Hour 30 Minutes

A $150 \mathrm{~mm}$ thick wall with a return angle is built at the workshop for students' practical test. The wall is to be given a $12 \mathrm{~mm}$ thick rendering and plastering on both faces and finished with a wooden float

The candidate is to batch and mix cement/sand mortar in the appropriate ratio for the wet finish. Marks will be awarded for the correct procedure of batching and mixing by hand (manual method), the elimination of unnecessary movement in carrying out the work piece as well as for the quality of work and the craftsmanship displayed.

\section{Assistance}

The candidate is provided Assistance for the conveyance of mortar and materials and the removal of waste as and when required.

\section{Materials}

Sand

Cement

Water

\section{Tools}

Steel trowel

Wooden float

Straight edge

Shovel

Spade

Head pan/Gauge box

Lath

\section{Working Area}

The recommended working area for each candidate is $4.5 \mathrm{~m} \times 2.7 \mathrm{~m}$ 


\section{Appendix C}

\section{MARKING SCHEME}

\section{ACHIEVEMENT TEST}

\section{Test Item Correct

Option/Answer

Test Item Correct Option/Answe

$1 . \quad-B$

$2 . \quad-D$

3. $-\mathrm{B}$

4. $\quad-\mathrm{A}$

$5 . \quad-\mathrm{C}$

$6 . \quad-B$

$7 . \quad-C$

$8 . \quad-D$

$9 . \quad-A$

$10 . \quad-D$

\section{PERFORMANCE TEST}

\section{Mortar Preparation}

Correct batching

-5 marks

Mixing twice dry

-5 marks

Mixing twice wet

-5 marks

Workable mortar

-4 marks

\section{Rendering and Plastering}

Provision of a key (Surface preparation)

-5 marks

Thickness

-5 marks

Flush face

-5 marks

External angle

-5 marks

Internal angle

-5 marks

\section{Craftsmanship Displayed}

Clean working, effective use of time, safety, judicious use o materials

-6 marks

Total

-50 marks 
The Comparative Instructional Effectiveness of Print-Based and Video-Based Instructional Materials for Teaching Practical Skills at a Distance - Donkor

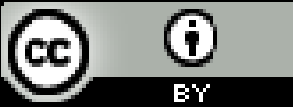

Athabasca University 